\title{
Early warning systems for food safety and integrity need to be anticipative to be useful for preventing food crisis situations
}

\author{
Franz Ulberth ${ }^{1}$
}

Published online: 21 July 2016

(C) Bundesamt für Verbraucherschutz und Lebensmittelsicherheit (BVL) 2016

The free movement of safe and wholesome food is an essential aspect of the EU internal market and contributes significantly to the health and well-being of EU citizens, and to their social and economic interests. Due to globalisation and the availability of new technological processes, the European food sector and the products and services offered are becoming more and more complex. Unfortunately, consumers' trust in food-triggered by a number of food scaresis still weak in several EU member states.

Food safety is a complex issue, has many facets, and requires the commitment of all stakeholders in the feed-food chain in order to place feed and food on the market that is not injurious to animal and human health. The food chain, however, does not stop at the point of sale, but at the consumption stage, where food is prepared and served by catering services or further stored and processed by the consumer at the household level. Food safety hazards can be introduced at any stage along the chain and the resulting risks need to be assessed and managed. Systems which allow detecting an emerging issue at an early stage are vital for informing risk manager, who have to deal with increasingly complex supply chains spanning the whole globe. The EU Rapid Alert System for Food and Feed (RASFF) was already started in 1979 with the aim of creating a platform for exchanging

Franz Ulberth

Franz.ULBERTH@ec.europa.eu

1 European Commission, Joint Research Centre, Geel, Belgium information among governments about identified risks in relation to food or feed and mitigation measures taken. Similar systems exist at the global [e.g. FAO/WHO International Food Safety Authorities Network (INFOSAN)] or national level (e.g. US FDA Reportable Food Registry). Although the usefulness of those systems is undisputed, they are reactive; they collect information about already manifested hazards/threats but have not the ability to detect weak signals of probably occurring food safety events before they unfold. Characteristic features of such pro-active early warning systems are horizon scanning, data gathering, intelligence assessment, networking with stakeholders and statistical modelling for identifying and/or predicting emerging risks. Such systems have been developed as part of research programmes funded by the European Commission (Marvin and Kleter 2009; Bouzembrak and Marvin 2016), the European Commission's Joint Research Centre (JRC) (Rortais et al. 2010), the European Food Safety Authority (Costa et al. 2016), or at national level (Müller et al. 2016).

Prevention of fraud in the agri-food chain and promotion of authentic products is a major element to assure the commercial success of European highvalue agricultural products on international markets. Loosing reputation in this area will negatively impact on competitiveness and profitability of farmers in the EU. On top, the basic right of European consumers to have access to authentic products has to be protected. Marketing standards and EU quality schemes shall ensure that consumer expectations are met and enables the functioning of the internal market and global trade in agricultural products. 
Agricultural products of high commercial value such as wine and spirits and certain edible oils have been long since the target for fraudulent malpractices, sugaring and watering of must and wine and admixture of foreign or refined oils to olive oil being most common. Recent opinion suggests that organised crime syndicates are increasingly behind cases of food fraud and adulteration. Consequently, the detection and prevention of food fraud requires strategic planning and investment at the national and EU level with a proportionate and sustainable budget. The European Commission created the Food Fraud Network (FFN) and an IT system, the Administrative Assistance and Cooperation system, for an efficient exchange of information related to suspicion of food fraud, which will be linked to other electronic information systems such as RASFF, TRACES, OFIS. Based on the MedISys tool, the JRC has created a media monitoring system (JRC Food Fraud Reporter) to search for signals of food fraud on the Internet to warn authorities of potentially developing food fraud cases.

In summary, to ensure the integrity of our food, supply predictive tools are necessary to complement the food safety surveillance systems in place in many countries. A number of initiatives are already underway at national and supra-national level which could benefit from exchange of best practice and cooperation. In addition to food borne hazards, aspects of fraudulent malpractices should be integrated in such pro-active food integrity warning systems to protect not only human health and wellbeing but also the financial interests of consumers.

\section{References}

Bouzembrak Y, Marvin HJP (2016) Prediction of food fraud type using data from Rapid Alert System for Food and Feed (RASFF) and Bayesian network modelling. Food Control 61:180-187

Costa MC, Goumperis T, Andersson W, Badiola J, Ooms W, Pongolini S, Saegerman C, Jurkovic M, Tuominen $P$, Tsigarida E, Steinwider J, Hölzl C, Mikushinska N, GrossBoskovic A, Kanari P, Christodoulidou M, Babicka L, Korsgaard H, Pesonen S, Fillet AM, Foures F, Lohman M, Luber P, Szabo M, Cseh J, Noteborn HPJM, Færden K, Fulke Å, Trnovec T, Ilbäck NG, Andersson T, Donohoe T, Merten C, Robinson T (2016) Risk identification in food safety: strategy and outcomes of the EFSA emerging risks exchange network (EREN), 2010-2014. Food Control. doi:10.1016/j.foodcont.2016.04.045

Marvin HJP, Kleter GA (2009) Early awareness of emerging risks associated with food and feed production: synopsis of pertinent work carried out within the SAFE FOODS project. Food Chem Toxicol 47:911-914

Müller B, Verhaelen K, Eberlein V, Ülker Celik B, Butzenlechner M, Busch U, Weidner C, Holtmannspötter H, Gilsbach W, Wallner P (2016) Etablierung eines Frühwarnsystems zur Erkennung lebensmittelbedingter Risiken in Bayernrisikoorientierte Lebensmittelüberwachung weiter gefasst. J Verbr Lebensm 11:9-18

Rortais A, Belyaeva J, Gemo M, van der Goot E, Linge JP (2010) MedISys: an early-warning system for the detection of (re-)emerging food- and feed-borne hazards. Food Res Int 43:1553-1556 